\section{International Scientific Journal Theoretical \& Applied Science}

p-ISSN: 2308-4944 (print) e-ISSN: 2409-0085 (online)

Year: 2015 Issue: 04 Volume: 24

Published: $30.04 .2015 \quad$ http://T-Science.org
Natalya Aleksandrovna Baburina assistant to department of biology, ecology, histology FGBOU VPO "The St. Petersburg state academy of veterinary medicine", Russia

Valentin Stanislavovich Ivanov candidate of veterinary sciences, associate professor, head of the department of biology, ecology, histology

FGBOU VPO "The St. Petersburg state academy of veterinary medicine", Russia walkat@pochta.ru

SECTION 11. Biology. Ecology. Veterinary. Entomology.

\title{
OCCURRENCE OF BARK BEETLES OF DIFFERENT TYPES IN VARIOUS OF THE WOODS OF THE LENINGRAD REGION
}

\author{
Abstract: The comparative analysis of specific structure of bark beetles in different types of the wood of the \\ Leningrad region is carried out. \\ Key words: bark beetle, occurrence, Leningrad region, entomofauna. \\ Language: Russian \\ Citation: Baburina NA, Ivanov VS (2015) OCCURRENCE OF BARK BEETLES OF DIFFERENT TYPES \\ IN VARIOUS OF THE WOODS OF THE LENINGRAD REGION. ISJ Theoretical \& Applied Science 04 (24): \\ 162-165.

\section{Soi: http://s-o-i.org/1.1/TAS*04(24)28 Doi: crossef http://dx.doi.org/10.15863/TAS.2015.04.24.28 \\ ВСТРЕЧАЕМОСТЬ КОРОЕДОВ РАЗНЫХ ВИДОВ В РАЗЛИЧНЫХ ТИПАХ ЛЕСОВ} \\ ЛЕНИНГРАДСКОЙ ОБЛАСТИ
}

Аннотация: Проведён сравнительный анализ видового состава короедов в разных типах леса Ленинградской области.

Ключевые слова: короеды, встречаемость, энтомофауна, Ленинградская область.

Сохранение и рациональное использование ресурсов среды, в том числе биологического разнообразия - одна из насущных современных задач.

Одним из первых этапов в решении этой проблемы является инвентаризация фауны и выявление пространственного распределения организмов. Полученные данные могут быть важны для мониторинга заражённости лесных массивов ЛО короедами с целью предотвращения расселения вредителей на новые участки леса.

В течение трёх лет, с 2012 по 2014 год, студенты под нашим руководством занимались сбором и определением насекомых, составлением фаунистических энтомологических коллекций и гербариев. были

Некоторыми направлениями нашей работы

1. Собрать и определить представителей жуков - короедов (Scolytinae) в различных типах лесов Ленинградской области.

2. Провести сравнительный анализ видового состава короедов в разных типах леса.

Методика сбора.
Сбор жуков проводили на пожелтевших, засыхающих и поваленных деревьях, встречающихся при визуальном осмотре. Этот способ сбора короедов является наиболее эффективным [1, с. 10, 3, с.6].

Тип леса определялся по преобладающему растению в древесном и в надпочвенных ярусах $[6$, c. 10].

Сборы проводились в следующих типах леса (по Гуленковой и Красниковой):

1. Ельник сфагновый(ЕС)

2. Ельник-кисличник( ЕК)

3. Ельник- черничник(ЕЧ)

4. Сосняк сфагновый(CC)

5. Сосняк черничный $(\mathrm{CЧ})$

6. Сосняк брусничный(СБ)

7. Сосняк лишайниковый(СЛ)

Сборы проводились в Подпорожском, Тихвинском, Всеволожском, Гатчинском и Лужском районах Ленинградской области. Всего собрано 114 особей, относящихся к 20 видам.

Из данных, изложенных в таб. 1 следует, что наиболее высоким видовым разнообразие короедов характеризовались ельники-кисличники (13 видов) и ельники-черничники (12 видов). 
Наибольшее число собранных особей приходится на ельники-черничники (29 шт.) и ельники- кисличники (28 шт.), наименьшее - на сфагновые ельники(6 особей).

Число видов короедов, обнаруженных в разных типах лесов.

Таблица 1

\begin{tabular}{|c|c|c|c|}
\hline Тип леса & Вид короеда & Число особей & $\begin{array}{c}\text { Место сбора (условия, вид повреждаемого } \\
\text { дерева, ярус повреждения) }\end{array}$ \\
\hline EC & \begin{tabular}{|l} 
Пушистый полиграф \\
Хвойный лесовик \\
Малый еловый полиграф \\
Пальцеходный лубоед \\
Большой еловый лубоед \\
\end{tabular} & $\begin{array}{l}2 \\
1 \\
1 \\
1 \\
1\end{array}$ & $\begin{array}{l}\text { Стволы сухих елей } \\
\text { Влажный бурелом } \\
\text { Ствол усохшей ели } \\
\text { Ствол усохшей ёлочки } \\
\text { Лапа старой ели }\end{array}$ \\
\hline EK & $\begin{array}{l}\text { Короед-типограф } \\
\text { Щетинистый лубоед } \\
\text { Гравёр обыкновенный } \\
\text { Хвойный древесинник } \\
\text { Фиолетовый лубоед } \\
\text { Большой еловый лубоед } \\
\text { Пушистый полиграф } \\
\text { Еловый корнежил } \\
\text { Пальцеходный лубоед } \\
\text { Малый еловый полиграф } \\
\text { Короед-двойник } \\
\text { Валежный короед } \\
\text { Обыкновенный микрограф } \\
\end{array}$ & $\begin{array}{l}5 \\
2 \\
3 \\
3 \\
3 \\
2 \\
2 \\
2 \\
2 \\
1 \\
1 \\
1 \\
1 \\
\end{array}$ & $\begin{array}{l}\text { Толстый бурелом ели } \\
\text { Усохшие ветви елей } \\
\text { Вершины усохших елей } \\
\text { Нижняя часть ствола ели } \\
\text { Пень ели } \\
\text { Корневая лапа старой ели } \\
\text { Затенённые стволы ели } \\
\text { Крупный корень ели } \\
\text { Ствол маленькой ёлочки } \\
\text { Ветвь усохшей ели } \\
\text { Верхушка ели } \\
\text { Пень ели } \\
\text { Ветка ели }\end{array}$ \\
\hline EЧ & \begin{tabular}{|l} 
Фиолетовый лубоед \\
Малый еловый полиграф \\
Многоядный древесинник \\
Короед-типограф \\
Пушистый полиграф \\
Гравёр обыкновенный \\
Хвойный древесинник \\
Щетинистый лубоед \\
Еловый корнежил \\
Большой еловый лубоед \\
Чёрно-бурый лубоед \\
Хвойный лесовик
\end{tabular} & $\begin{array}{l}4 \\
3 \\
4 \\
4 \\
2 \\
2 \\
2 \\
2 \\
2 \\
1 \\
2 \\
1\end{array}$ & $\begin{array}{l}\text { Свежие брёвна и пни } \\
\text { Стволы елей } \\
\text { Стволы берёз, осин } \\
\text { Ветви елей } \\
\text { Ветви елей } \\
\text { Мелкие ели } \\
\text { Бурелом } \\
\text { Усохшие ветви ели } \\
\text { Корни ели } \\
\text { Нижняя лапа ели } \\
\text { Бурелом } \\
\text { Корневые лапы ели }\end{array}$ \\
\hline $\mathrm{CC}$ & $\begin{array}{l}\text { Большой сосновый лубоед } \\
\text { Хвойный лесовик } \\
\text { Короед пожарищ } \\
\text { Малый лиственничный короед } \\
\text { Фиолетовый лубоед } \\
\end{array}$ & $\begin{array}{l}6 \\
3 \\
1 \\
1 \\
2\end{array}$ & $\begin{array}{l}\text { Стволы сосен } \\
\text { Влажный бурелом } \\
\text { Сосновый пень } \\
\text { Ствол сосны } \\
\text { Сосновые пни } \\
\end{array}$ \\
\hline $\mathrm{C4}$ & $\begin{array}{l}\text { Фиолетовый лубоед } \\
\text { Большой сосновый лубоед } \\
\text { Хвойный древесинник } \\
\text { Хвойный лесовик }\end{array}$ & $\begin{array}{l}3 \\
4 \\
6 \\
2\end{array}$ & $\begin{array}{l}\text { Стволы сосен } \\
\text { Стволы сосен } \\
\text { Бурелом, пни сосны } \\
\text { Комель сосны }\end{array}$ \\
\hline СБ & \begin{tabular}{|l} 
Фиолетовый лубоед \\
Большой сосновый лубоед \\
Хвойный древесинник \\
Гравёр двузубый \\
Короед пожарищ \\
\end{tabular} & $\begin{array}{l}4 \\
3 \\
3 \\
1 \\
1\end{array}$ & $\begin{array}{l}\text { Пни, брёвна сосен } \\
\text { Пни, брёвна сосен } \\
\text { Стволы сосен } \\
\text { Бурелом } \\
\text { Сосновый пень } \\
\end{array}$ \\
\hline СЛ & $\begin{array}{l}\text { Большой сосновый лубоед } \\
\text { Фиолетовый лубоед } \\
\text { Хвойный древесинник } \\
\text { Многоядный древесинник } \\
\text { Гравёр двузубый } \\
\end{array}$ & $\begin{array}{l}5 \\
2 \\
2 \\
1 \\
1\end{array}$ & $\begin{array}{l}\text { Стволы сосен, пни } \\
\text { Стволы сосен } \\
\text { Низ ствола сосен } \\
\text { Ствол берёзы } \\
\text { Мелкие ветки сосны } \\
\end{array}$ \\
\hline
\end{tabular}


Распределение встреченных нами в коллекциях видов Scolytidae по биотопам отражено в таблице 2.

Таблица 2

Распределение собранных короедов по биотопам.

\begin{tabular}{|c|c|c|c|c|}
\hline Вид & Всего & Тип леса & $\begin{array}{l}\text { Число собранных } \\
\text { особей }\end{array}$ & Место сбора \\
\hline $\begin{array}{l}\text { Пушистый полиграф } \\
\text { Polygraphus polygraphus }\end{array}$ & 6 & $\begin{array}{l}\text { EC } \\
\text { EK } \\
\text { EY }\end{array}$ & $\begin{array}{l}2 \\
2 \\
2\end{array}$ & $\begin{array}{l}\text { Затенённые стволы, ветви елей, } \\
\text { сухие стволы елей }\end{array}$ \\
\hline $\begin{array}{l}\text { Хвойный лесовик Dryocoetes } \\
\text { autographus }\end{array}$ & 7 & $\begin{array}{l}\mathrm{EC} \\
\mathrm{EY} \\
\mathrm{CC} \\
\mathrm{CY}\end{array}$ & $\begin{array}{l}1 \\
1 \\
3 \\
2\end{array}$ & $\begin{array}{l}\text { Влажный бурелом, корневые } \\
\text { лапы елей, комли сосен }\end{array}$ \\
\hline $\begin{array}{l}\text { Малый еловый полиграф } \\
\text { Polygraphus subopacus }\end{array}$ & 5 & $\begin{array}{l}\text { EC } \\
\text { EK } \\
\text { EY }\end{array}$ & $\begin{array}{l}1 \\
1 \\
3\end{array}$ & Ветви и стволы усохших елей \\
\hline $\begin{array}{ll}\text { Пальцеходный } & \text { лубоед } \\
\text { Xylechinus pilosus } & \end{array}$ & 3 & $\begin{array}{l}\text { EC } \\
\text { EK }\end{array}$ & $\begin{array}{l}1 \\
2\end{array}$ & Стволы маленьких ёлочек \\
\hline $\begin{array}{l}\text { Большой еловый } \\
\text { Dendroctonus micans }\end{array}$ & 4 & $\begin{array}{l}\text { EC } \\
\text { EK } \\
\text { EY }\end{array}$ & $\begin{array}{l}1 \\
2 \\
1\end{array}$ & Нижние лапы старых елей \\
\hline $\begin{array}{ll}\text { Kopoeд-типограф } \\
\text { typographus }\end{array}$ & 9 & $\begin{array}{l}\text { EK } \\
\text { EY }\end{array}$ & $\begin{array}{l}5 \\
4\end{array}$ & Ветви и бурелом елей \\
\hline $\begin{array}{ll}\text { Щетинистый } & \text { лубоед } \\
\text { Phloeotribus spinulosus } & \\
\end{array}$ & 4 & $\begin{array}{l}\text { EK } \\
\text { EY }\end{array}$ & $\begin{array}{l}2 \\
2 \\
\end{array}$ & Усохшие ветви елей \\
\hline $\begin{array}{ll}\text { Гравёр } & \text { обыкновенный } \\
\text { Pityogenes chalcographys }\end{array}$ & 5 & $\begin{array}{l}\mathrm{EK} \\
\mathrm{EY}\end{array}$ & $\begin{array}{l}3 \\
2\end{array}$ & $\begin{array}{lll}\begin{array}{l}\text { Вершинки мелких елей } \\
\text { усохших елей }\end{array} & \text { и } \\
\end{array}$ \\
\hline $\begin{array}{l}\text { Хвойный } \\
\text { Trypodendron } \\
\text { lineatum }\end{array}$ & 16 & $\begin{array}{l}\text { EК } \\
\text { ЕЧ } \\
\text { СЧ } \\
\text { СБ } \\
\text { СЛ }\end{array}$ & $\begin{array}{l}3 \\
2 \\
6 \\
3 \\
2 \\
\end{array}$ & $\begin{array}{l}\text { Бурелом, нижние части стволов } \\
\text { ели и сосны, пни ели и сосны }\end{array}$ \\
\hline $\begin{array}{l}\text { Фиолетовый лубоед Hylurgops } \\
\text { palliatus }\end{array}$ & 18 & $\begin{array}{l}\mathrm{EK} \\
\mathrm{EЧ} \\
\mathrm{CC} \\
\mathrm{CЧ} \\
\mathrm{CБ} \\
\mathrm{CЛ}\end{array}$ & $\begin{array}{l}3 \\
4 \\
2 \\
3 \\
4 \\
2 \\
\end{array}$ & Пни и брёвна хвойных деревьев \\
\hline $\begin{array}{ll}\text { Еловый корнежил } \\
\text { cunicularius }\end{array}$ & 4 & $\begin{array}{l}\text { EK } \\
\text { EY }\end{array}$ & $\begin{array}{l}2 \\
2\end{array}$ & Корни елей \\
\hline Короед-двойник Ips duplicatus & 1 & EK & 1 & Верхушка ели \\
\hline $\begin{array}{l}\text { Валежный короед Orthotomicus } \\
\text { proximus }\end{array}$ & 1 & ЕК & 1 & Пень ели \\
\hline $\begin{array}{l}\text { Обыкновенный } \\
\text { Pityophtorus micrographus }\end{array}$ & 1 & ЕК & 1 & Ветка ели \\
\hline $\begin{array}{l}\text { Многоядный древесинник } \\
\text { Trypodendron sygnatum }\end{array}$ & 5 & $\begin{array}{l}\text { EЧ } \\
\text { СЛ }\end{array}$ & $\begin{array}{l}4 \\
1\end{array}$ & Стволы берёз и осин \\
\hline $\begin{array}{l}\text { Чёрно-бурый лубоед Hylurgops } \\
\text { glabratus }\end{array}$ & 2 & EЧ & 2 & Бурелом \\
\hline $\begin{array}{l}\text { Большой сосновый } \\
\text { Tomicus piniperda }\end{array}$ & 18 & $\begin{array}{l}\mathrm{CC} \\
\text { CЧ } \\
\text { СБ }\end{array}$ & $\begin{array}{l}6 \\
4 \\
3\end{array}$ & Пни, стволы, брёвна сосен \\
\hline
\end{tabular}




\begin{tabular}{|l|l|l|l|l|}
\hline & & СЛ & 5 & \\
\hline $\begin{array}{l}\text { Короед пожарищ Orthotomicus } \\
\text { suturalis }\end{array}$ & 1 & СБ & 1 & Сосновый пень \\
\hline $\begin{array}{l}\text { Малый лиственничный короед } \\
\text { Orthotomicus laricis }\end{array}$ & 1 & СС & 1 & Ствол сосны \\
\hline $\begin{array}{l}\text { Гравёр двузубый Pityogenes } \\
\text { bidentatus }\end{array}$ & 2 & $\begin{array}{l}\text { СБ } \\
\text { СЛ }\end{array}$ & 1 & 1 \\
\hline
\end{tabular}

Такие виды, как Пушистый полиграф и Малый еловый полиграф, были встречены в нескольких биотопах (6 и 5 соответственно). Короед-двойник, Валежный короед, Обыкновенный микрограф, Чёрно-бурый лубоед, Гравёр двузубый и Короед пожарищ были менее распространены и отмечены лишь в одном биотопе каждый. Наиболее часто встречались Большой сосновый лубоед, Фиолетовый лубоед и Хвойный древесинник, что совпадает с данными полученными другими исследователями $(5$, с. 5 45, 10, с. 198-210). По литературным данным, наиболее опасным из них является Большой сосновый лубоед, так как он способен заселять стволы живых деревьев, ускоряя их гибель $[9$, c.20-24]

\section{Выводы:}

1. Наиболее высоким видовым разнообразие короедов характеризовались ельникикисличники и ельники-черничники. На эти же биотопы приходится и наибольшее число собранных особей,наименьшее приходится на сфагновые ельники.

2. В максимальном числе биотопов были встречены Пушистый полиграф и Малый еловый полиграф .

3. Наиболее часто встречались Большой сосновый лубоед, Фиолетовый лубоед и Хвойный древесинник.

\section{References:}

1. Baburina NA, Ivanov VS, Chumasov EI, Lunegova IV, Shhipakin MV (2012) Metodicheskie ukazanija po uchebnoj praktike dlja studentov 1 kursa fakul'teta FVM, SPb, Izdatel'stvo FGBOU SPbGAVM, 2012, pp. 514.

2. Izhevskij SS (2005) Illjustrirovannyj spravochnik zhukov- ksilofagov, vreditelej lesa i lesomaterialov Rossijskoj Federacii, Tula,Grif i K., 2005, pp.20-101.

4. Korotnev NI (1926) Koroedy, ih lesovodstvennoe znachenie i mery bor'by, Moscow, 1926, pp. 24-27.

5. Mandel'shtam MJ (1998) Novye dannye o faune koroedov (Coleoptera, Scolytidae) Leningradskoj oblasti. V: "Problemy jentomologii v Rossii." Sbornik nauchnyh trudov XI Sezda Russkogo jentomologicheskogo obshhestva (23-26 september 1997, Sankt-Peterburg). Zoologicheskij institut RAN. 1998. Tom 2. pp. 23-24.

6. Mandel'shtam MJ (2000) Annotirovannyj spisok vidov koroedov Leningradskoj oblasti,
Jentomologicheskoe obozrenie, 2000, t 79 vyp.3, pp. 5- 45.

7. Mozolevskaja EG, etc. (1991) Praktikum po lesnoj jentomologii, Moscow, Jekologija, 1991, pp. 10-18.

8. Stark VN (1952) Koroedy. Fauna SSSR. Tom 31. Izd-vo AN SSSR, 1952, pp. 36-39.

9. Sadovnikova TP (2012) Koroed-tipograf i metody bor'by $\mathrm{s}$ nim. Materialy dokladov mezhdunarodnogo simpoziuma "Zashhita rastenij - problemy i perspektivy", Kishinjov, 2012, pp.127-128.

10. Vasechko GI (1981) Vzaimodejstvie koroedov s kormovymi derev'jami, Moscow, 1981,VINITI, pp. 24-45.

11. Voolma K, Mandel'shtam MJ, Shherbakov AN, Jakovlev EB, Ounap H, Suda I, Popovichev BG, Sharapa TV, Galasjeva TV, Hajretdinov RR (2004) Raspredelenie i rasprostranenie Zhukov-koroedov v rajone Finskogo zaliva (lesa Jestonii, Finljandii i Severo-Zapadnoj Rossii). Entomologica Fennica. 2004. Vyp. 15, Nomer 4. - pp. 198-210. 